tion of thermodynamic functions given properly. From this point of view the treatment is admirable.

For the second class of user the treatment is, in the opinion of the reviewer, not so satisfactory, but his complaints are directed rather against the general fashion in thermodynamic exposition than against the book under review. He cannot help wishing that more attention had been devoted to giving a more logical exposition of the fundamentals on the basis of mechanical concepts without the introduction of undefined thermal concepts, somewhat after the manner shown to be possible by Born in his series of expository articles in the Physikalische Zeitschrift (1921), based on the ideas of Carathéodory, which Born greatly simplified. The reviewer fears he is fighting a losing battle over this. Few other students of thermodynamics appear to share his tastes and prejudices in this matter, but he is unrepentant. The logical beauty possible by the Born-Carathéodory approach is very great and extremely satisfying. The clarity gained by beginning the development of the theory of heat at the beginning with the Zeroth Law of Thermodynamies, the existence of temperature (on an empirical scale) with only the concepts of mechanics assumed a priori, is outstanding. But these admittedly are matters of taste.

Another matter of taste, on which the taste of the reviewer differs violently from the authors, is the introduction of absolute entropy. Now that the old abuses and errors associated with this idea have all been swept away, no great harm is done, if it is agreed that entropy can and shall be so defined that the entropy of every perfect crystal is zero at the absolute zero of temperature. There is no need to do so, but it is generally agreed that there is a gain in elegance in so doing. But the absolute entropy in common use is only absolute in a rather sophisticated way. What is of practical utility is almost always entropy statistically defined but with nuclear spin weight omitted, which has the limit zero in theory and practice when one extrapolates to zero ideal calorimetric measurements from any hitherto accessible temperature range. An absolute entropy which tends to zero at zero temperature for any material assembly is definable but probably not often practically realizable, and should be introduced with much circumspection. Nor need it be made the keystone of the Third Law of Thermodynamics, nor Nernst's Heat Theorem deduced therefrom. Such is the private taste of the reviewer-probably nowadays an unnecessary prejudice derived from scars on his mind caused by much study of the appalling nonsense written about absolute entropy in the days before Ehrenfest and Trkal showed how futile it is to discuss the dependence of entropy on the number of systems in an assembly without including means by which that number can be varied reversibly. Associated with the presentation of absolute entropy is the type of connexion adopted between the thermodynamic functions and their statistical counterparts. The connexion adopted here is to make the direct connexion in Boltzmann's manner between entropy and a suitably defined 'probability'. Again the reviewer must admit that he dislikes this method, and considers that the connexion should logically be made through the Second Law and showing that the statistical method provides two functions of the state of the matter in question with the right properties to play the parts of $T$ and $S$ in the equation $d Q=T d S$. This is again a matter of taste.
To sum up, mainly from the point of view of the instructed user, this is an extremely valuable book. The physical chemist who knows his way about it will be well equipped with the fundamentals of his trade. There is a good and comprehensive index, but in view of the scope and variety of subjects treated, one may perhaps regret that an elaborate table of contents was not provided as well. Perhaps this may be done in the next reprint. The book should be widely used.

R. H. FOWLER.

\section{WORLD FLORAS}

Geographical Guide to the Floras of the World

An Annotated Selected List of Floras and Floristic Works relating to Vascular Plants, including Bibliographies and Publications dealing with Useful Plants and Vernacular Names. Part 1 : Africa, Australasia, Insular Floras, North America and South America. By S. F. Blake and Alice C. Atwood. Pp. 336. (Washington: United States Dept. of Agriculture Miscellaneous Publication No. 401, 1942.) 75 cents.

A COMPREHENSIVE world list of regional floras $A$ has long been a desideratum. It is now halfway to being realized by the publication of this volume, the first of two parts which aim at providing "an annotated summary of the available, nominally complete publications on the vascular flora and the economic botany of the world", complete up to 1939 . No list of the scope of this one has previously been published. While it enumerates more than 3,000 titles, its aim is usefulness and not bibliographical completeness. Papers dealing with only a section of the flora of any region, monographs and revisions of genera or families, or those works which are primarily, ecological are excluded, as are all works of a 'popular' type intended for beginners.

The publications listed under each geographical area are arranged under two headings : first, general works covering the whole region, followed by local floras dealing with smaller areas within the greater. Each publication is listed in full only once, but crossreferences are provided. Annotations appended to each work indicate the scope of its contents, such as the presence or absence of information as to topography, geology and climate and exact geographical area covered where this is loosely conveyed in the title, data as to previous botanical exploration, ecological information, the inclusion of vernacular names and presence or absence of a bibliography. The total number of species described or listed in each work quoted is usually given.

The catalogue affords data for a summary of the knowledge of the floras of more than half the world, and such a summary is given indicating those regions with and without floras and those insufficiently known or inadequately covered by published works. Australasia and Greenland are the best served with systematic works; and South America, with half its countries lacking even a comprehensive list of species, is the least well known. It is more surprising to learn that in the United States "a severe critique might reduce to not more than about 13 the number of States with moderately satisfactory floras".

This is an invaluable reference work and the part dealing with Europe and Asia will be eagerly awaited. The detailed geographical index facilitates ease of reference, and there is also an index of authors.

W. A. Sledge. 